\title{
Another tool in the toolbox: A novel, multimodal, silver and surfactant- based skin cleanser vs. $62 \%$ ethanol on the human coronavirus OC43 on human tissue
}

\author{
Daryl S Paulson* \\ BioScience Laboratories, Inc., 1765 South 19th Avenue; Bozeman, MT 59718, USA
}

\begin{abstract}
Background: This study evaluated the persistent efficacy of a novel, multi- ingredient colloidal silver skin cleanser vs. $62 \%$ ethanol against the coronavirus as a proxy for SARS-CoV-2 to determine the ability of each to reduce the coronavirus viral load after timed reinoculation on intact forearm skin of human volunteers.

Methods: Five volunteer test subjects had the test and comparator products applied to their skin. After allowing the products to dry, the subjects had a known titer of the human coronavirus strain OC43 (ZeptoMetrix Corporation \#0810024CF) inoculated on treated skin sites located at randomized portions of the subjects' forearms and reinoculated with the virus again at 15 minutes, 30 minutes, 60 minutes, 120 minutes and 180 minutes post-treatment. Following each specified exposure time, samples were taken from the test sites and $\log _{10}$ reductions in the virus titer were compared to the baseline recovery.
\end{abstract}

Results: The Theraworx Protect product demonstrated post application improved virucidal activity to alcohol for both immediate and residual effects over time.

Conclusions: Both early and residual activity of the Theraworx Protect product against the coronavirus in reducing viral concentration was superior to the $62 \%$ ethanol solution.

\section{Introduction}

This study consists of the coronavirus.

The coronavirus has been on this planet for centuries and changes or mutates from time to time in order to survive. The COVID-19 is the strain of coronavirus that is causing the current pandemic. The virus's original host was animals, but in Wuhan, China, it switched hosts to humans. The virus mutated slightly in its replication process to become the COVID-19 strain, which is formally $2019-\mathrm{nCoV}$. It is an RNA (ribonucleic acid) virus, meaning that it needs the RNA in a human cell to reproduce. Through an electron microscope, it appears as an imperfect circle with portions that are erect or looks like a crown and, therefore, is termed the "corona" for "crown" virus (Figure 1).

The virus is composed of three simple structures:[1]

1. the inner core of ribonucleic acid,

2. a capsid or a shell around the inner core, and

3. glycoprotein spikes.

This year, the COVID-19 virus infected and maimed many individuals, and the pandemic is going strong.

Because this virus caught most countries, including the United States, unprepared with little scientific data regarding how to prevent its spread, immobilize it, and treat it.

The use of alcohol disinfectants as a tool for the hand sanitization of humans, including healthcare workers, has become a standard recommendation among public health officials to aid in preventing microorganism transmission during social interaction, as well as a

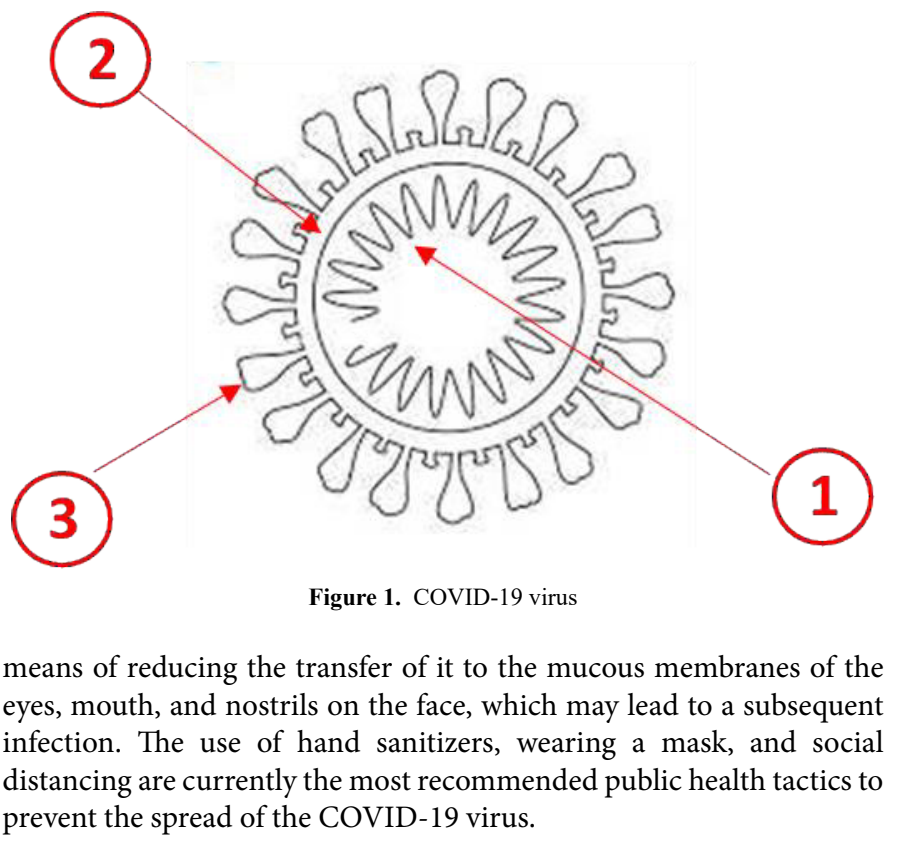

${ }^{\star}$ Correspondence to: Daryl S Paulson, BioScience Laboratories, Inc., 1765 South 19th Avenue; Bozeman, MT 59718, USA, E-mail: DPaulson@biosciencelabs.com

Key words: hand sanitizer, coronavirus, alcohol, colloidal silver

Received: September 11, 2020; Accepted: September 21, 2020; Published: September 30, 2020 
The most common alcohols used for skin disinfection are ethanol, isopropyl, and n-propanol, the latter being more popular in Europe than in the United States. Of the three, ethanol has been shown to be the most effective against viruses, but all three types of alcohol have shown reduced activity against this virus [2]. In general, higher concentrations of each type of alcohol have shown greater effectiveness, but elevated concentrations also can create serious issues with skin drying and damage to the stratum corneum. The most common public healthcare recommendation relating to the COVID-19 pandemic is the use of ethanol solutions of $60 \%-70 \%$ for hand sanitization.

With the importance of skin disinfection of the hands currently elevated because of the COVID-19 pandemic, the identification of effective alternatives to alcohol sanitizers can be an answer to the problems associated with alcohol-containing products. In addition to the skin drying and cracking caused by repeated application of ethanol because it removes the skin's oils, its frequent use can result in changes to normal skin flora and open the door to more frequent colonization by staphylococci and Gram-negative bacteria, alcohol has limited residual effects, as soon as it dries, there are no more antimicrobial actions, meaning frequent re- applications of alcohol-based hand sanitizers, which, in turn, causes more damage to the skin $[3,4]$.

Additionally, alcohol-based hand sanitizers may work well only in clinical settings, where hands are not heavily soiled or greasy. In fact, alcohol hand sanitizers can be ineffective in removing bacteria if too little is applied or if it is wiped off before it completely dries on the skin [5]. Once alcohol dries, there are no more antimicrobial effects.

Another safety issue with alcohol-based hand sanitizers is ingestion. Ethanol-based hand sanitizers can cause alcohol poisoning if a person swallows more than two mouthfuls. In a new report from CDC, researchers analyzed data reported to the National Poison Data System (NPDS) from 2011-2014 on exposures to alcohol and nonalcohol-based hand sanitizers in children who were 12 years old or younger, and 65,293 (92\% of reports) were alcohol-based exposures [6]. Emergency rooms nationwide have seen instances of both intoxication and hypoglycemia in children, and older children have been known to swallow hand sanitizers to become intoxicated purposely [7].

Another challenge with the use of alcohol-based hand sanitizers is that they present a significant flammability hazard, both in liquid form and as a vapor that can bleed off at higher temperatures. Alcohol-based hand sanitizers are classified as Class I Flammable Liquid substances, which means they have a flash point of less than 100 degrees Fahrenheit. If hand sanitizer combusts, carbon monoxide and carbon dioxide can form.

As has been said, we need another tool in the toolbox, which alcohol cannot be used. A safer, non-inferior alternative to alcoholbased sanitizers could help combat the transmission of COVID-19 with fewer side effects.

This product has been on the market for years, used in hospital intensive care units for skin and wound cleansing. The objective of this test evaluation was to compare the efficacy of a silver-based skin cleanser to $62 \%$ ethanol against a seasonal coronavirus as a proxy for SARS-CoV-2 to determine the ability of each to reduce the number of coronavirus particles on the intact forearm skin of volunteers.

\section{Materials and methods}

For this test, a surrogate coronavirus, human coronavirus strain OC43 (ZeptoMetrix Corporation \#0810024CF) was selected for ethical and safety considerations. The very similar morphological structure of these two coronavirus (both $\sim 30 \mathrm{~kb}$ genome size, both enveloped, positive-sense RNA viruses with protein spike, membrane and envelope imbedded in host-membrane derived lipid bilayer encapsulating the helical nucleoside comprising viral RNA) made the Cov- OC-43 virus a credible substitute for the COVID 19 virus in this test.

The comparator product was $62 \%$ ethanol $(\mathrm{v} / \mathrm{v})$ prepared by the $3^{\text {rd }}$ party testing laboratory (BioScience Laboratories, Inc.; Bozeman, MT) by adding $36.3 \mathrm{~mL}$ ( $95 \%$ ethanol (Everclear) as aseptically added to 68.2 $\mathrm{mL}$ of sterile deionized water in a sterile glass bottle. The contents were swirled to mix to result in $104.5 \mathrm{~mL}$ of $62 \%$ ethanol solution, stored at ambient temperature.

After undergoing a 7-day pre-conditioning period, during which subjects had not used any substance to affect the skin, five subjects had the test and comparator products applied to their skin. Only five subjects were employed, because, at this time, there was no credible information on how COVID-19 would be at this time of total shutdown.

After allowing to the product to dry on the skin, the subjects then had a known titer of the human coronavirus strain OC43 (ZeptoMetrix Corporation \#0810024CF) inoculated on treated skin sites located on the subjects' forearms. Randomized portions of the treated skin were repeatedly challenged with the virus at 15 minutes, 30 minutes, 60 minutes, 120 minutes, and 180 minutes post-treatment. Following each specified exposure time, samples were taken from the test sites and $\log _{10}$ of the $50 \%$ titration end point for infectivity. To calculate the viral titer, a $50 \%$ tissue culture infectious dose $\left(\mathrm{TCID}_{50}\right)$ calculation - the Quantal Test (Spearman-Kärber Method) - was applied.

$\operatorname{LogTCID}_{50}=L-d(s-0.5)$

where:

$L=-\log _{10}$ of the lowest dilution;

$d=$ Difference between dilution steps;

$S=$ Sum of proportions of positive wells.

The $\log _{10}$ reductions were calculated as follows:

$\log 10$ Reduction $=(\log 10$ TCID50 of the Baseline $)-(\log 10$ TCID50 of the Test Recovery)

The test protocols and consent forms were supplied to the Gallatin Institutional Review Board (GIRB) for review and approval, and the test was conducted in compliance with current Good Clinical Practice regulations, Good Laboratory Practice regulations (reference CFR 21, Parts 58), the standard operating procedures of BioScience Laboratories, Inc., the test protocol and any protocol amendments.

\section{Results}

For the analysis of this study, a blocked, two-factor Analysis of Variance (ANOVA) was used for the analysis. The model was:

$$
\hat{y}=\text { Blocks }+A+B+(A \times B)+e
$$

where:

$$
\hat{y}=\log _{10} \text { Reduction }
$$

Blocks $=$ Subjects (each subject received the two products, one on each arm, randomly)

\section{$\mathrm{A}=$ Products}

1, if Test Product (multimodal colloidal silver skin cleanser) 2, if Comparator Product (62\% ethanol alcohol) 
$\mathrm{B}=$ Sample Times

1 , if 15 minutes

2 , if 30 minutes

3 , if 60 minutes

4 , if 120 minutes

5, if 180 minutes $(\mathrm{A} \times \mathrm{B})=$ Interaction Term $\mathrm{e}=$ Error Term

The subjects were selected at random, but the product and sample times were "pre- determined," or chosen before the study began; hence, they were fixed effects Table $1 . \sqrt{s^{2}}$ The mean square error $\left(M S_{E}\right)$ adjusted, or the variance $\left(s^{2}\right)$ was 0.075 , which provided a standard deviation of $=\mathrm{s}=0.271$. All $F$-values evaluated were significant $(p<$ $0.05)$.

\section{Interactions}

The interaction between products and sample times was statistically significant $(p<0.001)$. Figure 2 demonstrates that at 15 and 30 minutes, there was a large difference between the Theraworx product (Test Product) and the $62 \%$ ethanol product (Comparator Product), with Theraworx having higher persistence. From 60 minutes to 180 minutes, the difference became less pronounced. The Test Product achieved greater persistence than the Comparator Product throughout the study.

\section{Comparisons for reduction - products}

In this portion of the evaluation, the two products were evaluated; the sample times were not measured, but they were kept in the model when the products were compared (Tables 2 and 3 ).

There was a statistically significant difference between the two products. The Theraworx product and $62 \%$ ethanol product were significantly different in persistence effects $(p=0.00)$ over all the sample times but leaving them in the model. The Theraworx product kept the virus counts down better than alcohol.

\section{Comparisons for reduction - sample times}

The sample times were compared, leaving the products in the model (Tables 4 and 5).

Grouping Information Using the Tukey Method and 95\% Confidence

\section{Means that do not share a letter are significantly different.}

At 15 and 30 minutes, the persistent effects of the Theraworx product over the ethanol were statistically significant $(p<0.05)$. After the 30-minute sample time through the 180 -minute sample time, the times were not statistically different. If a greater number of subjects were used, this would be statistically significant.

Table 1. General linear model

\begin{tabular}{|c|c|c|c|c|c|c|c|c|}
\hline Factor & Type & Levels & Values & & & & & \\
\hline SUBJECT & Random & 5 & $3,4,6,8,12$ & & & & & \\
\hline PRODUCT & Fixed & 2 & 1,2 & & & & & \\
\hline SAMPLE & Fixed & 5 & $1,2,3,4,5$ & & & & & \\
\hline Factor & Type & Levels & Values & & & & & \\
\hline \multicolumn{9}{|c|}{ Analysis of Variance for Reduction, using Adjusted Sum of Squares for Tests } \\
\hline Source & DF & Seq SS & Contribution & Adj SS & Adj MS & F-Value & P-Value & Significance \\
\hline Subject & 4 & 1.737 & $9.70 \%$ & 1.737 & 0.43437 & 5.76 & 0.001 & Significant \\
\hline Product & 1 & 5.611 & $31.34 \%$ & 5.611 & 5.61125 & 74.47 & 0.000 & Significant \\
\hline Sample & 4 & 5.912 & $33.02 \%$ & 5.912 & 1.47812 & 19.62 & 0.000 & Significant \\
\hline Product*Sample & 4 & 1.932 & $10.79 \%$ & 1.932 & 0.48312 & 6.41 & 0.001 & Significant \\
\hline Error & 36 & 2.713 & $15.15 \%$ & 2.713 & 0.07535 & & & \\
\hline Total & 49 & 17.906 & $100.00 \%$ & & & & & \\
\hline
\end{tabular}

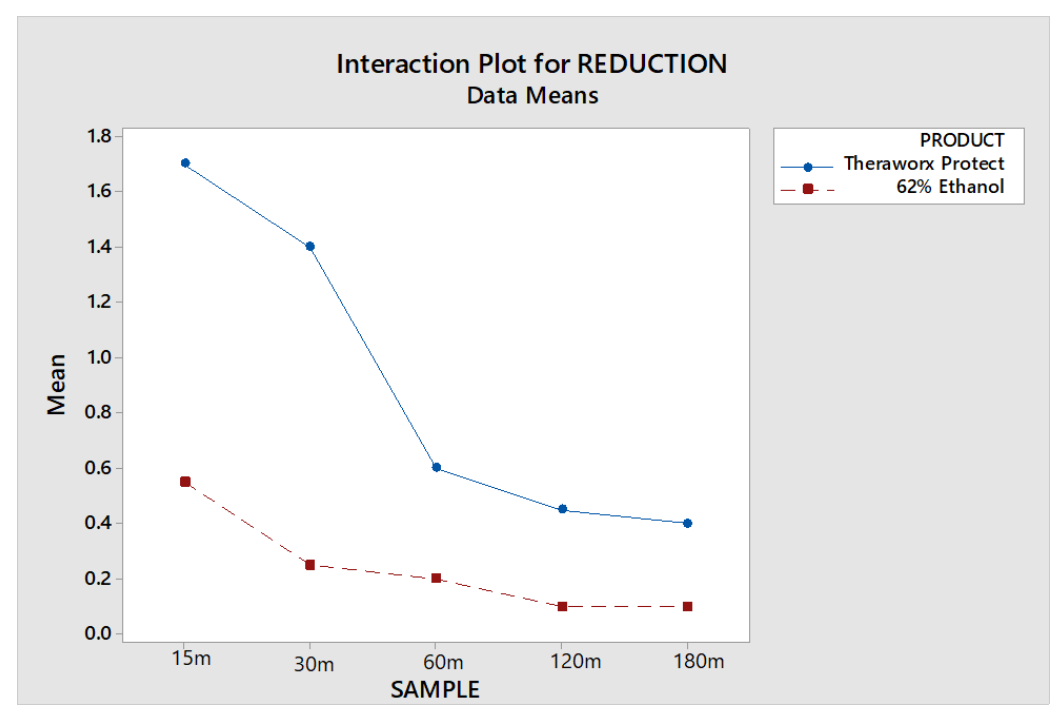

Figure 2. Interaction plot (Mean Log10 Reduction vs. Sample Time) 
Paulson DS (2020) Another tool in the toolbox: A novel, multimodal, silver and surfactant- based skin cleanser vs. 62\% ethanol on the human coronavirus OC43 on human tissue

However, the Theraworx product had greater persistence effects over the 60- minute through 180-minute sample times than the Comparator Product (62\% ethanol). There were not enough samples to justify this statistically.

Descriptive statistics are provided in Table 6, including sample size, means, standard deviations, and ranges.

\section{Discussion}

There was more residual activity of the Theraworx Protect product against the coronavirus in reducing viral concentration than the $62 \%$ ethanol solution. The viral load reductions shown by the Theraworx Protect product in this test can be contrasted to other viral reduction studies in two significant ways. First, many studies on viral load

Table 2. Tukey pairwise comparisons: Product

\begin{tabular}{|c|c|c|c|}
\hline Product & N & Mean & Grouping \\
\hline Test (Theraworx Protect) & 25 & 0.91 \\
\hline Comparator (62\% Ethanol) & 25 & 0.24 \\
\hline
\end{tabular}

Table 3. Tukey simultaneous tests for differences of means

\begin{tabular}{|c|c|c|c|c|c|c|}
\hline Difference of Product Levels & Difference of Means & SE of Difference & Simultaneous 95\% CI & T-Value & Adjusted P-Value & Significance (S/NS) \\
\hline $\begin{array}{l}\text { Comparator Product ( } 62 \% \text { Ethanol) } \\
\text { Test Product (Theraworx Protect) }\end{array}$ & -0.6700 & 0.0776 & $\begin{array}{c}(-0.8275,- \\
0.5125)\end{array}$ & -8.63 & 0.000 & $\mathrm{~S}$ \\
\hline
\end{tabular}

Table 4. Tukey pairwise comparisons: sample times

\begin{tabular}{|c|c|c|c|}
\hline Sample & $\boldsymbol{N}$ & Mean & Grouping \\
\hline 15 minutes & 10 & 1.125 & 0.825 \\
\hline 30 minutes & 10 & 0.400 & A \\
\hline 60 minutes & 10 & 0.275 & B \\
\hline 120 minutes & 10 & 0.250 \\
\hline
\end{tabular}

Table 5. Tukey simultaneous tests for differences of means

\begin{tabular}{|c|c|c|c|c|c|c|}
\hline $\begin{array}{c}\text { Difference of Sample } \\
\text { Levels }\end{array}$ & Difference of Means & SE of Difference & Simultaneous $95 \%$ CI & T-Value & Adjusted P-Value* & Significance \\
\hline 30 minutes -15 minutes & -0.300 & 0.123 & $(-0.652,0.052)$ & -2.44 & 0.127 & Not Significant \\
\hline 60 minutes -15 minutes & -0.725 & 0.123 & $(-1.077,-0.373)$ & -5.91 & 0.000 & Significant \\
\hline $\begin{array}{c}120 \text { minutes }-15 \\
\text { minutes }\end{array}$ & -0.850 & 0.123 & $(-1.202,-0.498)$ & -6.92 & 0.000 & Significant \\
\hline $\begin{array}{c}180 \text { minutes }-15 \\
\text { minutes }\end{array}$ & -0.875 & 0.123 & $(-1.227,-0.523)$ & -7.13 & 0.000 & Significant \\
\hline 60 minutes -30 minutes & -0.425 & 0.123 & $(-0.777,-0.073)$ & -3.46 & 0.011 & Significant \\
\hline $\begin{array}{c}120 \text { minutes }-30 \\
\text { minutes }\end{array}$ & -0.550 & 0.123 & $(-0.902,-0.198)$ & -4.48 & 0.001 & Significant \\
\hline $\begin{array}{l}180 \text { minutes }-30 \\
\text { minutes }\end{array}$ & -0.575 & 0.123 & $(-0.927,-0.223)$ & -4.68 & 0.000 & Significant \\
\hline 120 minutes -60 minutes & -0.125 & 0.123 & $(-0.477,0.227)$ & -1.02 & 0.845 & Not Significant \\
\hline 180 minutes -60 minutes & -0.150 & 0.123 & $(-0.502,0.202)$ & -1.22 & 0.739 & Not Significant \\
\hline $\begin{array}{c}180 \text { minutes }-120 \\
\text { minutes }\end{array}$ & -0.025 & 0.123 & $(-0.377,0.327)$ & -0.20 & 1.000 & Not Significant \\
\hline
\end{tabular}

* Significant $=p \leq 0.05 ;$ Not Significant $=p>0.05$

Table 6. Descriptive statistics - reductions

\begin{tabular}{|c|c|c|c|c|c|c|c|c|c|}
\hline \multicolumn{10}{|c|}{ Results for Product 1 (Test Product - Theraworx Protect) } \\
\hline Variable & Sample & $N$ & $N^{*}$ & Mean & SE Mean & StDev & Minimum & Maximum & Range \\
\hline \multirow[t]{5}{*}{ Log10 Reduction } & 15 minutes & 5 & 0 & 1.700 & 0.215 & 0.481 & 1.000 & 2.250 & 1.250 \\
\hline & 30minutes & 5 & 0 & 1.400 & 0.203 & 0.454 & 1.000 & 2.000 & 1.000 \\
\hline & 60 minutes & 5 & 0 & 0.600 & 0.203 & 0.454 & 0.000 & 1.250 & 1.250 \\
\hline & 120 minutes & 5 & 0 & 0.450 & 0.146 & 0.326 & 0.000 & 0.750 & 0.750 \\
\hline & 180 minutes & 5 & 0 & 0.400 & 0.127 & 0.285 & 0.000 & 0.750 & 0.750 \\
\hline \multicolumn{10}{|c|}{ Results for Product 2 (Comparator Product $-62 \%$ Ethanol) } \\
\hline Variable & Sample & $N$ & $N^{*}$ & Mean & SE Mean & StDev & Minimum & Maximum & Range \\
\hline \multirow[t]{5}{*}{ Log10 Reduction } & 15 minutes & 5 & 0 & 0.5500 & 0.0935 & 0.2092 & 0.2500 & 0.7500 & 0.5000 \\
\hline & 30minutes & 5 & 0 & 0.250 & 0.158 & 0.354 & 0.000 & 0.750 & 0.750 \\
\hline & 60 minutes & 5 & 0 & 0.2000 & 0.0935 & 0.2092 & 0.0000 & 0.5000 & 0.5000 \\
\hline & 120 minutes & 5 & 0 & 0.1000 & 0.0612 & 0.1369 & 0.0000 & 0.2500 & 0.2500 \\
\hline & 180 minutes & 5 & 0 & 0.100 & 0.100 & 0.224 & 0.000 & 0.500 & 0.500 \\
\hline
\end{tabular}


reduction are done in in-vitro models, looking at log reduction in virus-containing solutions. Historically, testing done on the same agent in such in-vitro models vs. skin models shows significantly greater $\log$ reduction in the in- vitro models. In fact, any greater than $1 \log$ reduction of viral load on a skin model is deemed very significant. Second, studies showing 3 log reductions in viral load typically utilize a 10-to-1 dilution in the initial viral inoculation, vs. this test in which there was no dilution in viral load in the initial inoculation.

Demonstrating an effective reduction in viral load, the Theraworx Protect product appears to be safer than alcohol-containing products for repeated use. In addition to being nonflammable, it can be used safely on mucous membranes. COVID-19 has made the public more aware of the importance of avoiding touching the face with one's hands, because of the possibility of transferring viral particles into the mouth, nose, or eyes, the entry points for respiratory viral infections [8].Theraworx Protect can be used not just as a hand disinfectant but also as a sanitizer around the "T- zone" (the eyes, nose, and mouth entryways for illnesses like COVID-19). The formula is non-toxic, safe, and gentle for use on the mucous membranes of the eyes, nose, and mouth. Plus, because Theraworx Protect is a low-pH formula containing surfactants and skin protectants, it also helps maintain the low-pH condition of healthy skin and can be used frequently without the potential for skin damage or drying over time.

\section{Conclusions}

This test attempted to compare the Theraworx product and alcohol to each other using the COVID-19 virus. While (depending on the disease) as few as 10 individual virus particles can cause infection, typical transmission events involve from 1,000 to 5,000 isolates. This test involved five instances of reinoculation of viral loads at a much higher level than the typical transmission event, and with lower transmission loads, demonstrating even more effectiveness in load reduction to safer levels.

The potential advantage of using Theraworx Protect in public health preventative practices associated with the current COVID-19 pandemic would seem to be significant, based on the results of this test. With some recent studies showing the COVID-19 virus persists longer with higher viral load and peaks later in the respiratory tissue of patients with severe disease [9], the ability to reduce viral load on the skin may have a positive impact on disease severity and therefore mortality.

More importantly, since COVID-19 can enter the body through the mucous membranes of the eyes, nose, and mouth, a safe and effective "face sanitizer" that is also a more effective hand sanitizer could be a welcomed new agent in the fight against not only COVID-19, but also influenza and other respiratory viruses and bacteria.

\section{References}

1. Flint J, Rancaniello VR, Rall GE, Skalka AM (2015) Principles of Virology, Vol. 1: Molecular Biology. [4 $4^{\text {th }}$ ed]. Washington, DC: ASM Press

2. Klein M, Deforest A (1983) Principles of viral inactivation. In: Block SS. Disinfection, sterilization and preservation. [ $3^{\text {rd }}$ ed]. Philadelphia, PA: Lea \& Febiger pp: 422-434.

3. Cook HA, Cimiotti JP, Della-Latta P, Saiman L, Larson EL (2007) Antimicrobial resistance patterns of colonizing flora on nurses' hands in the neonatal intensive care unit. Am J Infect Control 35: 231-236. [Crossref]

4. Kampiatu P, Cozean J (2015) A controlled, crossover study of a persistent antiseptic to reduce hospital-acquired infection. Afr J Infect Dis 9: 6-9. [Crossref]

5. Stebbins S, Cummings DA, Stark JH (2011) Reduction in the incidence of influenza A but not influenza B associated with use of hand sanitizer and cough hygiene in schools: A randomized controlled trial. Pediatr Infect DisJ 30: 921-926. [Crossref]

6. Santos C, Kieszak S, Wang A, Law R, Schier J, et al. (2017) Reported adverse health effects in children from ingestion of alcohol-based hand sanitizers - United States, 2011-2014. MMWR Morb Mortal Wkly Rep 66: 223-226. [Crossref]

7. Gold NA, Mirza TM, Avva U (2020) Alcohol Sanitizer. In: StatPearls Treasure Island (FL): StatPearls Publishing

8. WHO (2020) Rolling updates on coronavirus disease (COVID-19). Available at: https:// www.who.int/emergencies/diseases/novel-coronavirus-2019/events-as-they-happen.

9. Shufa Z, Jian F, Fei Y, Baihuan F, Bin L, et al. (2020) Viral load dynamics and disease severity in patients infected with SARS- CoV-2 in zhejiang province, china, JanuaryMarch 2020: retrospective cohort study BMJ 369: m1443. [Crossref]

Copyright: (2020 Paulson DS. This is an open-access article distributed under the terms of the Creative Commons Attribution License, which permits unrestricted use, distribution, and reproduction in any medium, provided the original author and source are credited. 